\title{
El problema de los robos: de los temores de la élite a las prácticas de subsistencia de los sectores subalternos. Mendoza (Río de la Plata), 1820-1831
}

\author{
por \\ Eugenia Molina \\ IDEHESI; Universidad Nacional de Cuyo
}

En este trabajo nos centramos en un estudio especifico de los robos ocurridos en la jurisdicción de Mendoza en el momento de conformación del estado provincial. Para ello analizaremos expedientes judiciales y documentos gubernamentales conservados en el Archivo Histórico de Mendoza. El objetivo del estudio apunta a determinar si los temores de la élite local, ante lo que ella interpretaba como una creciente conflictividad social pos revolucionaria, se correspondieron con lo planteado en las fuentes; no obstante, también buscamos detectar sobre qué atentados contra la propiedad focalizaron la vigilancia y punición.

PALABRAS ClaVe: criminalidad; robos; élites; sectores subalternos.

Una amplia producción historiográfica sobre el Río de la Plata, desarrollada a partir de la articulación entre historia social e historia jurídica, ha permitido conocer la trama de la experiencia judicial en sus instituciones, sus actores y sus discursos, en el largo plazo extendido entre la etapa tardocolonial y el período posrevolucionario ${ }^{1}$. Con diferentes referentes teóricos y metodológicos esta producción ha contribuido a la comprensión de la dinámica de la justicia junto con la estructura de las sociedades en las que se desplegaba, aportando elementos para conocer la composición de sus grupos, sus relaciones y conflictos. En este sentido, una de las categorías fundamentales que esa articulación disciplinar ha brindado ha sido la de la historicidad del delito y

${ }^{1}$ Referimos los textos más significativos por su reflexión teórico-metodológica y su propuesta de abordaje. Garavaglia, 1999a. Fradkin, 2007; 2009. Barriera, 2009; 2010. Salvatore, 2010. 
de la punición, en cuanto ha permitido insistir en el hecho de que los criterios con los cuales las sociedades han conceptualizado los comportamientos «desviados» de sus miembros y sus modos de tolerarlos, reprimirlos o corregirlos, han variado a lo largo de tiempo según las necesidades de éstas ${ }^{2}$.

Teniendo estas líneas historiográficas como marco de trabajo, ya con anterioridad hemos estudiado la conflictividad social en el inicio de la autonomía provincial a través del discurso de la élite expresado en los debates legislativos y la prensa, solicitando una justicia más dura y expeditiva; del mismo modo, intentamos reconstruir las series delictivas del período para ubicar estos pedidos en su propio contexto ${ }^{3}$. En este trabajo queremos volver sobre esta cuestión pero centrándonos en un abordaje específico de los robos, a partir de los expedientes hallados en el Archivo Histórico de Mendoza, Mendoza (en adelante AHM) ${ }^{4}$. El objetivo apunta a intentar determinar hasta qué punto los temores de esa élite se correspondieron con lo mostrado por las fuentes y detectar sobre qué comportamientos se focalizaron, siempre recordando que sólo disponemos de los delitos mínimamente judicializados, escapándosenos los resueltos por vías «infrajudiciales», «parajudiciales» y «extrajudiciales $\rangle^{5}$.

2 Las consideraciones sobre el modo en que los delitos violentos entre las personas fueron disminuyendo en contrapartida con los ataques contra la propiedad, los cuales fueron en aumento, en el amplio contexto de la modernidad, han tenido como referente la obra de Norbert Elias, 1978-1982. Sin embargo, no todos los autores están de acuerdo respecto de las evidencias empíricas que estarían demostrando la civilización de la violencia, ni menos aún sobre la categoría misma de violencia que debería ser utilizada. Resulta ilustrativo de las posturas historiográficas y epistemológicas en pugna, el debate desarrollado por dos de sus exponentes en una revista especializada en el tema: Spierenburg, 5/2 (Genève, 2001): 87-105. Schwerhoff, 6/2 (Genève, 2002): 103-126. Por su parte, no hace falta decir que respecto de la historicidad de los castigos, las representaciones que los fundamentaban y la intencionalidad sociopolítica de sus aplicaciones ha sido clave el trabajo de Michel Foucault, 1975; pero también otros textos suyos reunidos en compilaciones de disertaciones y cursos, tal como Foucault, 1996.

3 Molina, 2011b; 2011c.

${ }^{4}$ Los expedientes pertenecen a la sección judicial criminal (organizados según un doble orden alfabético y numérico), sección sumarios civiles y militares (carpetas 444 a 448), sección del juzgado del crimen (carpeta 431) y sección poderes ejecutivo y legislativo, correspondencia a alcaldes de primer y segundo voto (carpeta 414 y 415). En las citas, el primer número corresponderá a la carpeta y el segundo al documento.

5 La «infrajudicialidad» conforma una categoría que remite a procesos ritualizados fuera del aparato judicial para la solución de los conflictos interpersonales, en los cuales se apelan a sujetos mediadores con reconocimiento en sus comunidades, quienes en virtud de ese prestigio ejercen una función que apunta a mantener la armonía de las relaciones y restablecer su equilibrio cotidiano. Mantecón Movellán, 1/2 (Genève, 1998): 49-73. Se distinguiría de las categorías de «parajusticia» y la «extrajusticia» respecto del ceremonial público que implica- 
El período 1820-1831 recortado para este estudio se fundamenta en la especificidad que él presenta en relación con épocas precedentes y posteriores. En efecto, fue durante esos años cuando la élite local ensayó la conformación de un régimen republicano representativo que materializara la soberanía popular esgrimida desde la Revolución, esforzándose por ordenar una sociedad atravesada por la revolución y la guerra e intentando implementar, a la vez, los principios doctrinarios asumidos. Estos esfuerzos la condujeron a una serie de tensiones que comenzó a solucionar desde 1830, cuando con la ruptura del régimen institucional debido a los enfrentamientos unitario-federales que afectaron el equilibrio de poderes regional, se inclinó hacia la implementación de juicios sumarios que fueron dejando de lado aquellos principios declamados lo que le permitieron manejar mejor la lucha facciosa y el disciplinamiento de la sociedad. ${ }^{6}$ Este trabajo se centra, por el contrario, en la etapa previa a esta última, esto es, en la de la inicial organización provincial, cuando los discursos de los derechos individuales todavía se alternaban con el temor por los crímenes que habían cundido en la jurisdicción según la versión de la élite.

La exposición del análisis estará desarrollada en tres apartados. En el primero de ellos nos ocuparemos de reconstruir el perfil de los reos y sospechosos a partir de las variables de procedencia, ocupación, edad y estado civil; no obstante, también nos detendremos en los objetos robados, las circunstancias en las que se produjeron los sucesos y las estrategias defensivas utilizadas por los sujetos una vez ante la justicia. En el segundo, focalizaremos la atención en los castigos impuestos, tratando de determinar cuáles comportamientos fueron los más duramente penados y por qué razón. Finalmente, cerraremos con algunas consideraciones que recojan las conclusiones de este trabajo y sus relaciones con otros estudios locales y regionales.

\section{LA «OLA» DE ROBOS EN LA MIRILLA: LOS SUJETOS Y SUS ESTRATEGIAS}

La reconstrucción delictiva para el período recortado ha mostrado que los robos conformaron el 34\% de los delitos judicializados y que, aun con los matices que siempre requieren las cuantificaciones, superaron ampliamente a los otros dos delitos predominantes: homicidios $(20,5 \%)$ y heridas $(13,5 \%)^{7}$.

ban sus gestos y discursos, lo mismo que su objetivo estabilizador comunitario. Para una distinción de estas categorías, Garnot, 4/1 (Genève, 2000): 103-120.

${ }^{6}$ Molina, 2010: 83-105.

7 Molina, 2012. 
No obstante, su mayor concentración se produjo al comienzo de la década, cuando llegaron a la justicia de primera instancia hasta 18 denuncias anuales:

Cuadro 1. Robos Judicializados, 1820-1829

\begin{tabular}{|c|c|}
\hline Años & Robos \\
\hline 1820 & 8 \\
\hline 1821 & 17 \\
\hline 1822 & 18 \\
\hline 1823 & 8 \\
\hline 1824 & 6 \\
\hline 1825 & 4 \\
\hline 1826 & 2 \\
\hline 1827 & 7 \\
\hline 1828 & 7 \\
\hline $1829 *$ & 1 \\
\hline TOTAL & 78 \\
\hline
\end{tabular}

* Este año está claramente sub representado en los expedientes judiciales, pues el resto de las fuentes indican que fue un año de extrema conflictividad. Así, a comienzos de 1829, el gobernador Corvalán había ordenado fusilar a quien se le probase el robo de un peso o más. Seghesso de López Aragón, 1997: 103. De hecho, ello debía estar vinculado con los mismos sucesos político-militares conectados con la lucha regional unitario-federal, la cual condujo al desplazamiento forzado del mismo Corvalán en agosto de ese año. Hudson, 2008, vol II: 161229.

Fuente: elaboración propia a partir de AHM, Judicial Criminal, Sumarios Civiles y Militares (carpeta 444-448), Correspondencia a los alcaldes de primer y segundo voto (carpeta 414, 415), Juzgado del Crimen (carpeta 431).

Comparada la cantidad con la de otras épocas, los temores de la élite no parecían exagerados, pues en los diez años revolucionarios (1810-1819) sólo se habían judicializado $21 \operatorname{casos}^{8}$, mientras que en las últimas cuatro décadas coloniales (1770-1810) los jueces solamente actuaron 54 causas en todo el período ${ }^{9}$. No obstante, las cifras de este crecimiento de los robos deben ser matizadas al menos por dos factores fundamentales: por un lado, con el aumento demográfico, y por otro, con la consolidación de la red de justicia menor en la jurisdicción provincial, encargada de recibir las denuncias y re-

8 Molina, 6 (Rosario, 2009): 133-153.

9 Molina, 41 (Buenos Aires, enero-junio 2011a): 192-197. 
mitir los reos a la cárcel. En efecto, la población había crecido un $51,8 \%$ entre los dos censos (1812 y 1822), y si bien no se puede establecer una ecuación directa entre crecimiento poblacional y de la criminalidad, puede pensarse que existió cierta proporcionalidad. También la multiplicación de decuriones en el espacio rural y urbano había ya habituado a los vecinos a acudir a ellos por delitos y conflictos interpersonales, permitiendo que una vigilancia más efectiva canalizara hacia la justicia formal situaciones que antes podrían haberse solucionado fuera de ella (infrajusticia, parajusticia o extrajusticia). De todos modos, aun matizando la cuestión, si articulamos el total de robos del período con la cantidad de población, se ve que ellos afectaron a un $0,38 \%$ de los habitantes lo cual representaba una duplicación respecto del porcentaje para la década revolucionaria (que era de $0,15 \%$ ), dándonos una primera explicación de ese «sentimiento» de inseguridad ${ }^{10}$ que manifestaba la élite en los argumentos que fundamentaban sus solicitudes de una justicia más dura y expeditiva que hemos visto en trabajos anteriores.

Pero a ello se podría agregar que no sólo se trataba de que hubiera más atentados contra la propiedad, sino que la justicia menor, «de proximidad», fuera más atenta a la hora de vigilar y recibir las quejas de vecinos y moradores ${ }^{11}$. En este sentido, esos estudios previos muestran que el hábito de recurrir al juez inferior, denominado «decurión» en Mendoza, en situaciones de conflictos interpersonales ya se había consolidado durante la gestión sanmartiniana.

Ahora, si un aumento en el número de sustracciones era sentido y temido por la élite, ya fuera porque efectivamente había más actos de este tipo o porque estuviera más aceitada la vigilancia cotidiana judicial, sería interesante plantearse qué era lo que más le preocupaba: quiénes robaban, los objetos que tomaban, los procedimientos utilizados o las épocas en las que se producían los hechos. Veamos.

El perfil de los sospechosos y reos encontrado en los documentos judiciales se diferenciaba sólo en parte del reconstruido para otros espacios rioplatenses $^{12}$, pero se asemejaba bien al de otros. En este registro, como en Buenos Aires, prevalecieron los varones jóvenes, solteros y migrantes, que vivían de

10 Kessler, 2009.

11 Darío Barriera ha llamado la atención sobre la productividad del análisis de la «justicia de proximidad» para enfoques historiográficos que aborden los procesos de territorialización tardocoloniales o los de centralización estatal, en cuanto refiere a recursos para la solución de conflictos que no sólo garantizaba cercanía física sino también sociocultural. Barriera, 2012.

12 En Tucumán, la mayoría eran naturales de la jurisdicción y no había un predominio claro de los solteros; sí, en cambio, eran predominantemente jóvenes (entre 16 y 30). Parolo, 2009: 187-188. 
la venta de su fuerza de trabajo ${ }^{13}$. En 67 casos, 38 tenían hasta 25 años, 16 contaban entre 25 y 35 años, 7 entre 35 y 50, y 6 con más de esta última edad. A su vez, de 53 situaciones individualizadas, 32 fueron solteros y 21 casados. Respecto de la procedencia, de 61 sólo 13 eran nacidos en Mendoza, mientras que 25 habían venido de otras provincias rioplatenses, 22 de Chile y uno de Europa. Finalmente, de 69 ocupaciones, 32 declararon ser peones, 10 artesanos, 9 esclavos ${ }^{14}$, 6 labradores, 4 militares/milicianos, 3 arrieros, un escribiente, un carnicero y un criado. También hubo mujeres en al menos 6 casos, ocupándose de la tarea de ocultar objetos o de venderlos, siendo 2 esclavas y 2 esposas que ayudaron a sus maridos ${ }^{15}$, mientras que en una causa se trató de una señora (tenía el apelativo de «doña») que con su criada hurtó una pulpería aprovechando el desorden urbano generado por la expedición de Francisco del Corro en $1820^{16}$. Hasta aquí, entonces, una respuesta conocida: los sujetos arrestados pertenecían al grupo que la élite trataba de disciplinar laboralmente y fijar espacialmente en el marco de un mercado de trabajo de ritmos estacionales que los sometía a una crónica inestabilidad en los contra$\operatorname{tos}^{17}$.

Los animales (caballos, mulas, vacas y bueyes) fueron objetos de hurto en 34 ocasiones, mientras que prendas diversas y ropa lo fueron en 17, alimentos y bebidas en 9 (de la misma forma que dinero y oro), y en 8 se trató de efectos de plata y aperos. No obstante, en varias situaciones el robo de caballos implicó más bien el de la cabalgadura o de una parte de ella, pues el ejemplar había sido devuelto al momento de la prisión ${ }^{18}$. Así, a diferencia de los casos estudiados por Ricardo Salvatore en la campaña bonaerense, aquí sólo en 6

13 Salvatore, 2010: 73. Belzunces, 2011: 98-110.

14 Es claro que esta categoría no refería a una ocupación sino a una condición jurídica articulada con componentes étnicos; no obstante, la contabilizamos en una instancia separada equivalente a otras ocupaciones porque así aparece en las fuentes y se deduce de las propias calificaciones y clasificaciones de quien elaboraba el sumario, como también así aparecía en las declaraciones de los mismos testigos. Sobre la complejidad del status jurídico de la población esclava y liberta durante el período, Candioti, 2009.

15 Junio de 1821, AHM, carpeta 445, doc. 6; octubre de 1825, AHM, carpeta 446, doc. 16.

16 Octubre de 1820, AHM, carpeta $\mathrm{CH}-1$, doc. 19.

17 Las migraciones estacionales formaban parte de las estrategias de subsistencia de los grupos familiares subalternos que, en determinados períodos de las trayectorias vitales de sus miembros varones, apelaban a la movilidad como medio para obtener recursos para la parentela. Excelentes trabajos que dan cuenta de estos procesos de subsistencia son Faberman, $3^{\circ}$ serie/11 (Buenos Aires, 1995): 33-59. Boixadós y Faberman, $3^{\circ}$ serie/31 (Buenos Aires, 2009): 11-42.

18 Julio de 1822, AHM, carpeta 445, doc. 26. 
situaciones la intención fue el uso como transporte para huir de la justicia ${ }^{19} \mathrm{y}$ nunca para hacerlo por deserción, ${ }^{20}$ mientras que en escasas 3 oportunidades se trató del tráfico de caballadas y mulas para su comercialización previa remarcación ${ }^{21}$. De esta forma, de un conjunto de 17 robos, 14 implicaron la sustracción de sólo 1 ó 2 ejemplares buscados por estar ensillados ${ }^{22}$, usándose esos elementos para la reventa o directa apuesta en juego ${ }^{23}$, aunque los objetivos de transporte y apropiación de aperos no siempre fueron excluyentes ${ }^{24}$.

Tanto el destino dado a los aperos y a los animales como al de los efectos enajenados en pulperías, muestran que estos actores apuntaban a proveerse de metálico o a intercambiarlos por otros objetos ${ }^{25}$ en una época en la que se ha insistido demasiado en la escasez de circulante ${ }^{26}$. En este sentido, tomaban abanicos, guantes, encajes, cintas, géneros, que luego eran vendidos en otras tiendas; aunque también insertaban ilegalmente al circuito al menudeo bebidas, trigo y harina ${ }^{27}$. Este comercio clandestino les permitía disponer de dinero justamente en meses en los que la falta de paga o contratación no les permitía obtener recursos para la subsistencia. Por ejemplo, un freno se llegaba a vender a $\$ 6$ y un estribo a $\$ 9$, mientras que 2 bueyes lo podían ser en $\$ 14$ y un caballo y 2 mulas en $\$ 13^{28}$, lo cual brindaba montos semejantes a

19 Marzo de 1827, AHM, carpeta R-1, doc. 6.

20 Junio de 1821, AHM, carpeta G-1, doc. 12 .

21 Marzo de 1828, AHM, carpeta 447, doc. 20; junio de 1828, AHM, carpeta 447, doc. 23; noviembre de 1828, AHM, carpeta G-1, doc. 13.

22 Octubre de 1822, AHM, carpeta C-7, doc. 28; Julio de 1828, AHM, carpeta 447, doc. 25 .

23 Julio de 1821, AHM, carpeta 445, doc. 9; 1827, AHM, carpeta G-6, doc. 7.

24 Manuel Aguilera, por ejemplo, robó un caballo ensillado en Chacras de Coria y recorrió unos $30 \mathrm{~km}$ hasta Barriales, donde se deshizo de los aperos para venderlos, dejando suelto al animal. Noviembre de 1822, AHM, carpeta A-1, doc. 27.

25 Un chileno procesado por robar ropa, intentó regresar a su patria en una mula que había pagado con unos estribos de plata, posiblemente robados, aunque el suceso porque el cual fue apresado tenía que ver con el hurto de prendas. No obstante, es sintomático que los hechos fueran en enero, época en que el derretimiento de las nieves permitía el paso a Chile, mostrando cómo estos actos conformaron una estrategia de este peón para obtener recursos que le permitieran volver a su tierra. Enero de 1828, AHM, carpeta 447, doc. 17.

26 En la última década ha sido discutida la tesis consagrada por la historiografía que había sostenido la escasez de circulante y la crisis económica en el período posrevolucionario, mostrándose, por el contrario, las distintas variantes desplegadas en procesos de diversificación e inversión productiva y comercial que permitieron a ciertos actores salir airosos de este contexto. Bragoni, 2003: 280-296.

27 Noviembre de 1820, AHM, carpeta 444, doc. 44

28 Julio de 1821, AHM, carpeta 445, doc. 9; setiembre de 1821, AHM, carpeta 445, doc. 12; setiembre de 1826, AHM, carpeta E-2, doc. 4; marzo de 1828, AHM, carpeta 447, doc. 20. 
los de un acuerdo laboral, el que por varios días se pagaba en $\$ 12^{29}$. No es casual que en los años con mayor concentración de robos, 1821 y 1822, estos fueran denunciados precisamente entre junio y setiembre, cuando la demanda de mano de obra bajaba y llevaba a quienes vivían de la venta de su fuerza de trabajo a utilizar estrategias de subsistencia alternativas ${ }^{30}$, aumentando la vulnerabilidad de estos sujetos una procedencia foránea que no les permitía el acceso a la protección brindada por los vínculos parentales y comunita$\operatorname{rios}^{31}$.

La sustracción de vacas y bueyes respondía también a esta complementación de recursos laborales con la reventa del ganado en pie, carne, sebo y cueros, o directamente su consumo en el marco familiar. Así, recordemos la relevancia que tenía este producto en la alimentación y, por ello, también para el fisco, el cual oscilaba entre asegurar el abastecimiento y gravarlo, porque su consumo regular garantizaba ingresos a un tesoro público en permanente déficit $^{32}$. En este sentido, se entiende que teniendo en cuenta el cuadro de restricciones que el control del ramo imponía a la matanza de animales y a su venta para vigilar el cumplimiento de las condiciones impositivas, ${ }^{33}$ sumado a la retracción natural de la oferta en los meses centrales del año cuando los rodeos se suspendían para el engorde del ganado en invernada, fuera bastante habitual que los moradores carnearan ilegalmente reses que ofrecían a los carniceros ${ }^{34}$, e incluso que éstos mismos fueran acusados de robo ${ }^{35}$. De hecho, si el consumo en casa permitía disponer de alimento por varios días ${ }^{36}$, también la venta de cueros y sebo servía para lograr ingresos adicionales en el grupo familiar ${ }^{37}$. Era común, no obstante, la diversificación de lo hurtado,

29 Marzo de 1815, AHM, carpeta 442, doc. 15.

30 Junio de 1821, AHM, carpeta E-1, doc. 28. También en 1827 y 1828 los robos en tiendas y de elementos de aperos en esos meses mostraban su uso para venta e intercambio por falta de otros recursos por la contracción estacional del mercado laboral. Junio de 1827 , AHM, carpeta A-1, doc. 23; julio de 1828, AHM, carpeta 447, doc. 25.

31 Di Meglio, 17 (Salta, 2006a): 15-49. Garavaglia, 1999b: 29-56.

32 Las tensiones entre hacienda pública, proveedores, carniceros y consumidores puede seguirse en los debates legislativos. Actas del 12-3-1821, 19-12-1821, 22-3-1822, 17-1-1823. Academia Nacional de la Historia, 1988, vol. I: 17, 41, 53, 89. Una situación similar ha sido estudiada para Tucumán. Parolo, 2009: 154-162.

33 Un reo afirmó haber carneado reses de noche por no poder pagar los derechos de matanza. Noviembre de 1821, AHM, carpeta 445, doc. 14.

34 Noviembre de 1820, AHM, carpeta 444, doc. 43.

35 Octubre de 1820, AHM, carpeta M-2, doc. 19.

36 Julio de 1822, AHM, carpeta 445, doc. 28; setiembre de 1823, AHM, carpeta A-4, doc. 28 .

37 Abril de 1825, AHM, carpeta 446, doc. 11. 
consumiendo parte en el hogar, vendiendo otra y dando el resto como segmento de pago a los peones, mientras que el sebo y los cueros también se comercializaban $^{38}$.

De todos modos, si la intención de subsistencia fue predominante, en ocasiones pudo existir también otro objetivo: así, uno reo afirmó que decidieron con su compañero matar un animal cuando volvían de una fiesta, como una forma de extender la diversión; incluso, concretado el hecho, se llevaron sólo parte de la carne para charquearla, dejando el resto en el lugar $^{39}$. En otro caso, a su vez, también 2 bueyes fueron matados para abandonar la carne y el cuero, y ello cuando corría en pleno el mes de julio, época de gran escasez de este producto ${ }^{40}$. En este sentido, cabría pensar si estas acciones podrían categorizarse de «infrapolíticas» en el sentido de James Scott ${ }^{41}$, como podrían serlo también ciertos hurtos de caballos en los que los reos conocían bien quiénes eran los dueños y lo tomaron sin un objeto explícito para abandonarlo o devolverlo luego ${ }^{42}$; no obstante, en estos últimos casos también pudo tener que ver también un concepto más laxo de la propiedad privada que evidenciaba sus tensiones con el sostenido por la élite ${ }^{43}$, del mismo modo que desafíos al honor masculino, estrechamente vinculado al caballo.

Del mismo modo que ocurría con la carne hurtada, diversificada entre la venta a los tenderos y el consumo personal y familiar, también las ropas y géneros eran reincorporados al circuito mercantil, mientras algunos artículos pasaban a nutrir la vestimenta misma de los reos: ponchos, calzones, camisas y sombreros eran tomados para uso propio ${ }^{44}$, a la vez que las telas servían para confeccionar prendas de las cuales no disponían o estaban ya viejas ${ }^{45}$ : En este sentido, conviene recordar que el costo de estos productos era muy elevado, lo cual explica su rápida comercialización y/o apropiación, sobre todo cuando se trataba de materiales importados desde fuera del Río

38 Octubre de 1820, AHM, carpeta M-2, doc. 19; Octubre de 1820, AHM, carpeta 444, doc. 39; setiembre de 1823, AHM, carpeta A-4, doc. 28.

39 Junio de 1821, AHM, carpeta E-2, doc. 7.

40 Sólo se llevaron el sebo. Julio de 1821, AHM, carpeta G-1, doc. 29.

41 Scott, 2000.

42 Un peón chileno residente en Reducción tomó a sabiendas el caballo del alcalde menor de Luján y decidió ir a visitar a su madre en San Juan. A la vuelta devolvió el animal a su dueño, aunque sin pellón ni jerga. Junio de 1821, AHM, carpeta G-1, doc. 12.

43 Salvatore, 2010: 73-74.

44 Octubre de 1820, AHM, carpeta H-1, doc. 8; enero de 1821, AHM, carpeta 445, doc. 1 , marzo de 1822, AHM, carpeta 445, doc. 21.

45 Abril de 1821, AHM, carpeta B-3, doc. 3; marzo de 1824, AHM, carpeta 446, doc. 2. 
de la Plata a los cuales resultaba imposible acceder a los sectores subalternos ${ }^{46}$.

Sin embargo, como dijimos, también fueron robados dinero, plata y oro en un contexto en el que la falsificación de moneda se convirtió en un problema endémico que llegó a afectar la estabilidad institucional de la flamante provincia ${ }^{47}$. Ahora, si existe un rasgo propio de este tipo de robo fue que en él siempre medió algún grado de fuerza, quizá no siempre física contra personas, pero sí para el acceso al lugar en el que estaban los artículos. El uso de ganzúas exigía, además, una logística más sofisticada que el simple hurto que caracterizaba la extracción de animales. Así, en al menos tres casos los reos confirmaron el uso de llaves maestras ${ }^{48}$ y en uno llegaron a actuar con una violencia inusitada ${ }^{49}$.

No obstante, el balance muestra que la apelación al atentando físico no fue común, en general, en los ataques contra la propiedad, ya que de 78 casos, en 27 no hubo contacto entre ladrón y víctima sino que se trató específicamente de «hurtos». De hecho, en sólo 12 casos hubo mediación de la violencia pues se usaron elementos para romper o abrir cerraduras o hubo escalamiento ${ }^{50}$, y solamente en sólo 5 los reos provocaron heridas a las víctimas ${ }^{51}$. Los horarios de los delitos también tuvieron que ver con las modalidades utilizadas, pues mientras los forzamientos materiales ${ }^{52}$ y los robos con violencia fueron de noche ${ }^{53}$, los de cuatropea solían ser al amanecer o a la siesta $^{54}$.

En cuanto a las estrategias delictivas, las personas implicadas y los vínculos que las unían, la mayor cantidad de casos implicaron actos espontáneos o de poca previsión, tal como lo ha observado Belzunces en la sociedad de la

46 Di Meglio, 2006b: 48-49.

47 El gobernador Pedro Molina fue desplazado por una movilización que tuvo como marco la crisis financiera entre abril y junio de 1824. Un sugerente análisis que articula la crisis de legitimidad institucional con la cuestión económica en Bragoni, 2004, vol. III: 211218.

48 Agosto de 1825, AHM, carpeta 446, doc. 13.

49 En un asalto domiciliario a la medianoche, la familia fue golpeada y atada. Febrero de 1827, AHM, carpeta 447, doc. 7.

50 Noviembre de 1820, AHM, carpeta 444, doc. 44; noviembre de 1823, AHM, carpeta O-2, doc. 28; agosto de 1825, AHM, carpeta 446, doc. 13.

51 Junio de 1820, AHM, carpeta 444, doc. 32; marzo de 1822, HM, carpeta 445, doc. 21.

52 AHM, carpeta 447, doc. 28.

53 Agosto de 1825, AHM, carpeta 446, doc. 13; febrero de 1827, AHM, carpeta 447, doc. 7.

54 Marzo de 1828, AHM, carpeta 447, doc. 20. 
Guardia de Luján ${ }^{55}$. En este sentido, en 28 causas los reos declararon haber actuado solos ${ }^{56}$ o con un compañero ${ }^{57}$, y sólo en 10 integraron grupos de 3 o más con cierta logística más organizada. Respecto de los primeros, una invitación a robar en una pulpería podía constituir el paso anterior al acto mismo, mientras que el ocultamiento, distribución y venta de los objetos requirió mayor planeación, pues a mayor diversificación ${ }^{58}$ más probabilidades de escapar de la justicia menor y los ojos de los vecinos. A su vez, los expedientes analizados revelan que un circuito ilegal se dirigía directamente a San Juan para ubicar animales ${ }^{59}$ y efectos, implicando, es claro, algún intermediario que realizase la venta en esa jurisdicción ${ }^{60}$, mientras que otro de vacunos se distribuía en la campaña mendocina a través de diversos parajes, mostrando una muy elevada movilidad de los sectores subalternos ${ }^{61}$.

No obstante, si bien hubo grupos más o menos organizados ${ }^{62}$, sólo podemos hablar de gavillas como las descriptas por Di Meglio para Buenos Aires $^{63}$, en un solo caso ${ }^{64}$. Así, en general, los reos no tenían en el robo su única actividad, declarando oficios y ocupaciones ${ }^{65}$ que alternaban con el delito. Incluso, en los actos con forzamiento, el procedimiento implicó la integración temporal de un herrero al grupo ${ }^{66}$, o la asociación esporádica

55 Belzunces, 2011: 78.

56 Noviembre de 1820, AHM, carpeta 444, doc. 43; junio de 1821, AHM, carpeta 445, doc. 8 .

57 Febrero de 1821, AHM, carpeta 445, doc. 3; setiembre de 1821, AHM, carpeta 445, doc. 12 .

58 Julio de 1822, AHM, carpeta 445, doc. 26.

59 Noviembre de 1827, AHM, carpeta G-1, doc. 13.

60 Parecieron constituirse redes de comercio ilegal entre Mendoza y San Juan, tal como lo reveló el expediente que procesó a Rosendo Astorga por robo de dinero en una tienda, pero que terminó reconociendo otros actos en otras pulperías y mostrando cómo estos artículos eran reinsertados en la vecina ciudad cuyana. Noviembre de 1820, AHM, carpeta A-6, doc. 19.

${ }^{61}$ Mariano Barrera, por ejemplo, extrajo 5 vacas de Barriales y la vendió en Chacras de Coria, a $30 \mathrm{~km}$ entre sí. Junio de 1821, AHM, carpeta 445, doc. 8 .

62 1821, AHM, carpeta 445, doc. 6; febrero de 1827, AHM; carpeta 447, doc. 7.

63 Di Meglio, 2006a: 15-49.

64 Setiembre de 1824, AHM, carpeta S-4, doc. 25.

65 Ventura Avendaño era carnicero. Noviembre de 1820, AHM, carpeta 444, doc. 43. Martín Espinoza, era peón y había robado para disponer de dinero u objetos para empeñar en juegos. Enero de 1821, AHM, carpeta 445, doc. 1. Mariano Barrera, se declaró soldado. Junio de 1821, AHM, carpeta 445, doc. 8 .

66 Uno de los robos más importantes por el volumen de dinero y metales tomados, implicó a un grupo de 3 a 4 sujetos, que incluía a dos herreros, cuyo oficio sirvió para el forzamiento de la puerta. Aquí la sociabilidad de procedencia resultó clave, pues todos eran chilenos que residían en el mismo barrio. Agosto de 1825, AHM, carpeta 446, doc. 13. 
con un baqueano que ayudara a derivar animales por terrenos poco conoci$\operatorname{dos}^{67}$.

Los tres factores que favorecían las asociaciones en los casos que no fueron individuales eran las relaciones de parentesco (padres e hijos, hermanos, cónyuges, amancebados), las procedencias comunes en los no naturales de la jurisdicción (y hemos visto que eran predominantes en los atentados contra la propiedad) y los espacios laborales compartidos ${ }^{68}$. Las primeras eran rápidamente percibidas por los vecinos, de allí que fuera común, sobre todo en la campaña, en las denuncias por abigeato, que fueran acusados todos los varones de una familia ${ }^{69}$. Y resulta interesante ver cómo la logística respetaba, de algún modo, la jerarquía de sangre, por cuanto el padre o hermano mayor era quien dirigía el robo y decidía la distribución del botín ${ }^{70}$. A su vez, el rol del lugar de nacimiento y la jornada laboral compartida también resultaban claves, pues la sociabilidad en una pulpería ${ }^{71}$ cuando no se tenían vínculos en el lugar de residencia estacional ${ }^{72}$, las labores diarias ${ }^{73}$ y el recorrido en una tropa de carretas $^{74}$, conformaban condiciones suficientes para un acuerdo ${ }^{75}$, aunque esa misma fragilidad de lazos explica los conflictos al repartir lo robado ${ }^{76}$. El peso de la población esclava no resultó relevante en el total de los delitos (vimos que de 69 casos, sólo 9 involucraron a ésta), ni tampoco la solidaridad creada por esta condición a la hora de organizar estrategias delictivas. Así, encontramos esclavos asociados con pobladores libres ${ }^{77}$, y sólo vimos 2 grupos de ellos reunidos con el fin explícito de robar: un dúo para hurtar artículos de la bodega del dueño y revenderlos en una pulpería ${ }^{78}$ y un conjunto de esclavos, libertos y criados que asaltaron una pulpería a medianoche durante la inestabilidad política de la lucha unitario-federal de setiembre de $1829^{79}$.

67 Marzo de 1828, AHM, carpeta 447, doc. 20.

68 En otros espacios sociohistóricos se ha podido constatar claramente esta articulación entre procedencias, ocupaciones comunes y tipos delictivos. Ver Fontaine, 1/1 (Genève,1997): 71-85.

69 Julio de 1822, AHM, carpeta 445, doc. 28.

70 Noviembre de 1821, AHM, carpeta 445, doc. 14.

71 Julio de 1821, AHM, carpeta G- 1, doc. 29; junio de 1827, AHM, carpeta A-1, doc. 23.

72 Junio de 1821, AHM, carpeta E-1, doc. 28; enero de 1828, AHM, carpeta 447, doc. 17.

73 Febrero de 1827, AHM, carpeta 447, doc. 7.

74 Marzo de 1824, AHM, carpeta 446, doc. 2.

75 Setiembre de 1821, AHM, carpeta 445, doc. 12; marzo de 1822, AHM, carpeta 445, doc. 21; agosto de 1825, AHM, carpeta 445, doc. 13.

76 Enero de 1828, AHM, carpeta 447, doc. 17; junio de 1821, AHM, carpeta E-1, doc. 28.

77 Noviembre de 1823, AHM, carpeta O-2, doc. 28.

78 Setiembre de 1822, AHM, carpeta P-2, doc. 11.

79 Setiembre de 1829, AHM, carpeta F-1, doc. 5. 
Los argumentos defensivos de los reos una vez presentados ante la justicia formal, revelaban un claro conocimiento de los elementos que podían servirles de atenuantes, sobre todo cuando se los acusaba de la sustracción de animales $^{80}$. Así, cuando reconocieron su culpabilidad (y 19 lo hicieron), no negaron la propiedad ajena sino que se movieron en los márgenes que su respeto les dejaba. De esta forma, cuando se trató de caballos afirmaron haberlos devuelto a sus dueños habiéndolos tomado sólo «prestados»» ${ }^{81}$, o dijeron no conocerlos por haberlos hallado sueltos en la calle ${ }^{82}$; cuando fueron vacunos, en cambio, sostuvieron que mataron reses que no estaban marcadas ${ }^{83} \mathrm{o}$ lo hicieron porque molestaban en sus propiedades ${ }^{84}$. No obstante, en 18 ocasiones los acusados rechazaron imputaciones y se defendieron diciendo que inicialmente habían reconocido el hecho sólo por temor o vergüenza ${ }^{85}$, o también sosteniendo que se comprometían a pagar el animal en caso de individualizarse su dueño ${ }^{86}$.

Estas estrategias, sin embargo, no servían para los hurtos en pulperías o en domicilios pues en ella resultaba clara la violación del espacio privado. Allí los recursos defensivos consistieron, entonces, en desviar la culpabilidad hacia otros. En este registro, la «invitación ${ }^{87}$ pasaba de un reo a otro, pues quien había pergeñado la idea era considerado «más» culpable, disminuyendo la carga punitiva sobre el resto de los imputados ${ }^{88}$. Otro argumento al que se apeló fue la no utilización de violencia al cometer el hecho, afirmando los reos que las puertas estaban abiertas ${ }^{89}$, que existía una tapia baja que facilitó el acceso ${ }^{90}$ o que tenían una relación cercana con la víctima que les había

80 Estas estrategias discursivas de defensa dan cuenta de la circulación de una cultura jurídica letrada entre los sectores subalternos, la cual podía ser incorporada a partir de diversas experiencias de vida (estancias en la cárcel, acceso a la justicia formal como testigo o acusado) y se transmitía de modo oral sin necesidad de registros escritos que la fijasen o de lecturas, teniendo en cuenta que se trataba de sujetos que eran mayormente analfabetos. $\mathrm{Al}$ respecto, Barriera, 2008: 347-368.

81 Julio de 1821, AHM, carpeta 445, doc. 9; enero de 1822, AHM, carpeta G-6, doc. 36.

82 Junio de 1822, AHM, carpeta H-1, doc. 4.

83 Noviembre de 1821, AHM, carpeta 445, doc. 14.

84 Octubre de 1820, AHM, carpeta 444, doc. 39.

85 Julio de 1821, AHM, carpeta 445, doc. 9.

86 Febrero de 1821, AHM, carpeta 445, doc. 3.

87 La apelación a la «invitación» como defensa también funcionaba en los abigeatos. Junio de 1821, AHM, carpeta E-2, doc. 7.

88 Agosto de 1825, AHM, carpeta 446, doc. 13; enero de 1828, AHM, carpeta 447, doc. 17.

89 Marzo de 1828, AHM, carpeta 447, doc. 21.

90 Enero de 1828, AHM, carpeta 447, doc. 17. 
hecho pensar que no se molestaría si tomaba algunas de sus pertenencias ${ }^{91}$. Incluso, no se olvidaron de recordar al fiscal la devolución de los efectos a sus dueños para mitigar la pena ${ }^{92}$, y hasta negaron las acusaciones, afirmando que habían obtenido los artículos en juegos, aunque con ello corrían el riesgo de ser imputados por «mal entretenimiento» ${ }^{93}$.

En efecto, cuando esta acusación aparecía se convertía para los sujetos en un verdadero problema, del mismo modo que la figura jurídica emparentada a ella: la de vago, y ambas podían ser agregadas por los decuriones al remitir los presos $^{94}$, aunque ello no siempre fue la regla. En estos casos, era clave lograr demostrar alguna ocupación reconocida ${ }^{95}$, aunque ello era difícil para forasteros con contratos laborales estacionales, los cuales hemos visto, eran los sospechosos y reos más comunes en los delitos de robo. No obstante, tanto éstos como los locales se defendieron de la imputación de «ladrón ratero», negando el robo ${ }^{96}$, afirmando que era la primera vez que lo hacían ${ }^{97} \mathrm{o}$ aceptando los cargos sin resistencia para intentar obtener con ello piedad del juez y mitigar el castigo ${ }^{98}$. No obstante, en todos estos casos, los testimonios de vecinos y decuriones lograban desarmar los argumentos esgrimidos por los reos en la medida en que remitían a una «opinión» fundamentada en la «decencia» ${ }^{99}$, la cual claramente no podían esgrimir aquéllos.

ARgumentos y CRITERIOS A LA HORA DE CASTIGAR: ENTRE LA TOLERANCIA, LA VINDICACIÓN Y LA PREVENCIÓN

Una mirada comparativa de las penas impuestas a los robos permite ver que los que tuvieron como objeto el dinero y el oro, fueron aquellos para los cuales se dispusieron las más graves. En este sentido, se aplicaron en estos

\footnotetext{
91 Abril de 1821, AHM, carpeta B-3, doc. 3.

92 Marzo de 1824, AHM, carpeta 446, doc. 2.

93 Un esclavo procesado por el robo de un estribo y unos pañuelos se defendió diciendo que los obtuvo en juegos de azar y logró liberarse del castigo, siendo su amo el apercibido por la mala conducta de un sujeto a quien debía vigilar y contener. Julio de 1827, AHM, carpeta 447, doc. 12 .

94 Abril de 1821, AHM, carpeta B- 3, doc. 3; Julio de 1821, AHM, carpeta 445, doc. 9; julio de 1823, AHM, carpeta 445, doc. 42.

95 Junio de 1822, AHM, carpeta A-6, doc. 29; julio de 1823, AHM, carpeta D-1, doc. 12.

96 Abril de 1825, AHM, carpeta 446, doc. 11.

97 Noviembre de 1820, AHM, carpeta 444, doc. 43; noviembre de 1822, AHM, carpeta A-1, doc. 27.

98 Junio de 1821, AHM, carpeta 445, doc. 8.

99 Noviembre de 1822, AHM, carpeta A-1, doc. 27.
} 
casos de 200 a 50 azotes más el presidio (de 10 años a 3 meses) o penas infamantes tales como el tradicional paseo en burro ${ }^{100}$. En segundo lugar de dureza estuvieron las puniciones a los salteos en pulperías o los robos de alimentos y prendas dentro de domicilios, las cuales podían llegar a 200 azotes y servicio, y hasta 50 azotes con destierro (perpetuo o temporal). Los hurtos de animales, en cambio, se castigaron con azotes que fueron de los 15 a los 50 o presidio de sólo 15 días a 2 meses. Según esta distribución de castigos, parecería, entonces, que la preocupación central de la élite estaba en reprimir y evitar las sustracciones que afectaban el comercio y el circulante monetario que, dada la falsificación, era vigilado con mayor esfuerzo, mientras que el abigeato no pasaba de ser un delito molesto que, al menos por el momento, no era el más perseguido judicialmente.

El problema de la falsificación y la escasez de circulante pudieron llevar a que el robo de dinero, plata y oro fueran severamente castigados, como marcamos, pero también es claro que estos actos implicaron el uso de violencia interpersonal, de llaves maestras y escalamientos que implicaron la violación del espacio privado o doméstico ${ }^{101}$. Por ello es probable también que fueran castigados con ejemplaridad para evitar su reproducción, eliminando de la comunidad al reo en los casos más graves ${ }^{102}$, acción punitiva en la cual el peso de la tradición jurídica indiana resultó clave ${ }^{103}$.

No obstante, los actos en pulperías también resultaron penados con dureza en cuanto afectaban el control gubernamental del circuito mercantil. En este sentido, los artículos robados eran reinsertados rápidamente en él, dificultando la distinción del origen de los productos en una economía que tenía en el tráfico comercial el resorte básico de la hacienda pública ${ }^{104}$. Los jueces distinguían, sin embargo, entre quienes lo hacían en forma aislada por «necesidad» ${ }^{105}$, de quienes parecían habituados a actividades que amenazaban un

100 Febrero 1828, AHM, carpeta F-3, doc. 27.

101 Un reo fue penado con 50 azotes por entrar a una casa en la noche; el argumento de que la puerta estaba abierta no le sirvió para mitigar el castigo. Marzo de 1828, AH; carpeta 447 , doc. 21. Otro fue sentenciado a la misma cantidad más destierro por haber entrado de noche a la celda de un fraile y robar un escritorio. AHM, carpeta 447, doc. 28.

102 Junio de 1822, AHM, carpeta S-2, doc. 28; Noviembre de 1822, AHM, carpeta A-1, doc. 27; 1828, AHM; carpeta 447, doc. 28.

103 Gutiérrez, 1819, vol. III: 89.

104 Junio de 1821, AHM, carpeta E-1, doc. 28. La penalización de la compra de productos de origen desconocido venía desde décadas atrás, pero en 1820 un Reglamento de Policía había vuelto a insistir en ello. Un proceso de octubre de 1825 remitía a él para multar a quienes habían adquirido elementos de procedencia dudosa. AHM, carpeta 446, doc. 16.

105 La tradición indiana reconocía la «necesidad» como atenuante del robo. Gutiérrez, 1819, vol. III: 83. 
mercado vigilado. La «profesionalidad» implicaba la reiteración ${ }^{106}$ pero también jugaba en ella la violencia, de la misma manera que en el robo de dinero y metales. Así, la máxima pena que encontramos fue para un peón sanjuanino que en forma recurrente había robado pulperías, y ella consistió en 200 azotes ante las tiendas en las que lo había hecho, más servicio «en la Marina» a discreción del juez; a dos de sus colegas les cupo 100 azotes y 2 años de presidio, mientras que a su cómplice más reciente le dieron 50 azotes y presidio ${ }^{107}$. También un grupo de esclavos y libertos recibieron penas similares, de entre 200 y 100 azotes por sustraer efectos de un negocio con vista al mercado sanjuanino ${ }^{108}$, mientras que un puntano con su paisano recibieron sólo 50 azotes por lo mismo, aunque no teniendo antecedentes y habiendo procedido con improvisación y sin violencia ${ }^{109}$, tal como lo había hecho un gañán que fue castigado con nada más que 15 azotes por hurtar aguardiente del depósito de su patrón ${ }^{110}$.

Como adelantamos, la cuestión de los abigeatos pareció no conformar la mayor preocupación de la élite pues, incluso, la mayor cantidad de azotes que hemos visto para estos casos se vinculó más con la incorporación de agravantes (reincidencia, juego, amancebamiento, vagancia), que con la cantidad de animales tomados en cada hecho ${ }^{111}$. También los jueces tuvieron en cuenta el destino que se había dado a éstos, ya que una cosa era matarlos para consumirlos en casa y otra robarlos para revenderlos en pie o como artículo a los carniceros. En este sentido, el robo de 3 vacas fue penado con sólo 25 azotes ${ }^{112}$, amparándose en el Decreto de abril de 1746 para hurtos menores ${ }^{113}$, mientras que el de 3 vacas y 2 bueyes lo fue con 50, habiendo sido sustraídos de unos potreros para comercializarlos en otros ${ }^{114}$; a su vez, la matanza de animales ajenos y la venta de su carne y sebo se penó con 25 azotes y destierro por 2 años de la localidad ${ }^{115}$, y la misma cantidad de azotes con 3

\footnotetext{
106 Octubre de 1825, AHM, carpeta 446, doc. 16.

107 Junio de 1821, AHM, carpeta 445, doc. 6.

108 Setiembre de 1829, AHM, carpeta F-1, doc. 5.

109 Junio de 1827, AHM, carpeta A-1, doc. 23.

110 Junio de 1821, AHM, carpeta E-1, doc. 28.

111 Así, se penó el robo de un caballo devuelto pero sus aperos enajenados con 50 azotes, pero mediando la nota de «ladrón ratero» con la que había sido remitido a la cárcel. Julio de 1822, AHM, carpeta 445, doc. 26.

112 Junio de 1821, AHM, carpeta E-2, doc. 7; setiembre de 1822, AH; carpeta P-4, doc. 23.

113 Gutiérrez, 1819, vol. III: 96.

114 Setiembre de 1826, AHM, carpeta B-1, doc. 14; setiembre de 1826, AHM, carpeta E-2,
} doc. 4.

115 Octubre de 1820, AHM, carpeta M-2, doc. 19. 
meses de servicio (pues el juez de alzada rebajó los 4 pedidos por el fiscal) sirvió de castigo a un soldado que había robado 5 vacunos ${ }^{116}$. Incluso, el robo y muerte de una ternera en una zona predominantemente ganadera como Valle de Uco, al sur de la jurisdicción en la frontera indígena, fue sólo compensada con su pago al dueño sin otro agregado que el traslado del reo a la ciudad por un corto tiempo ${ }^{117}$, o con la prisión sufrida y el pago del animal en otro caso ${ }^{118}$. En resumen, las penas por abigeato no fueron las más altas, pues nunca superaron los 50 azotes y hasta llegaron a disminuirse al pasar al juez la solicitud del fiscal ${ }^{119}$.

Sí es claro que junto con la compensación de la víctima, la punición tenía un sentido ejemplificador, pues intentaba evitar la reproducción de las prácticas delictivas. En los robos de animales fue común, en este sentido, el pago de los ejemplares muertos al dueño acompañado con algunos azotes ${ }^{120}$, pero también podía sumarse la presencia de los cómplices menores en el castigo de los mayores responsables para que el horror del acto los inhibiera en el futuro de imitar su comportamiento ${ }^{121}$. Pero en los robos de efectos, también solía agregarse a los azotes el tradicional paseo en burro previo a la ejecución de la sentencia en el lugar del delito ${ }^{122}$, en la plaza principal «para escarmiento del delincuente, y exemplo de los mal intencionados» ${ }^{123} \mathrm{y}$ «para que todos lo sepan que quien tal haze, tal pague» ${ }^{124}$.

Una mención aparte merece la solicitud de pena de muerte para los implicados en el robo de artículos en una tropa de carretas que venía desde Buenos Aires en $1824^{125}$, pues tal pedido era discordante con las penas pedidas y aplicadas por robos. Además resulta peculiar porque se trataba del hurto de alimentos (azúcar, yerba) y géneros, la mayor parte de los cuales ya habían

116 Junio de 1821, AHM, carpeta 445, doc. 8.

117 Febrero de 1821, AHM, carpeta 445, doc. 3.

118 Setiembre de 1823, AHM, carpeta A-4, doc. 28.

119 Junio de 1821, AHM, carpeta 445, doc. 8; noviembre de 1821, AHM, carpeta S-2, doc. 25; marzo de 1828, AHM, carpeta 447, doc. 20.

120 Julio de 1822, AHM, carpeta 445, doc. 28.

121 Junio de 1821, AHM, carpeta 445, doc. 6; noviembre de 1821, AHM, carpeta 445, doc. 14; julio de 1822, AHM, carpeta 445, doc. 28; noviembre de 1822, AHM, carpeta A-1, doc. 27. Para un estudio sobre las formas de escenificación de los castigos como recurso de disciplinamiento social, Spierenburg, 1984. Mantecón Movellán, vol. III, 2012: 1905-1932.

122 Marzo de 1822, AHM, carpeta 445, doc. 21; octubre de 1825, AHM, carpeta 446, doc. 16 .

123 Junio de 1827, AHM, carpeta A-1, doc. 23.

124 Octubre de 1820, AHM, carpeta H-1, doc. 8.

125 Marzo de 1824, AHM, carpeta 446, doc. 2. 
sido devueltos al momento de la denuncia. El alegato del fiscal ${ }^{126}$ se insertaba, no obstante, en el discurso de la élite de los años previos que insistía en que la extensión del delito conformaba el síntoma de una desarticulación social, de allí la necesidad de un castigo ejemplar: «(...) hace años que la administración de justicia está en abandono, (...) se ha visto la casa invadida de hombres maliciosos, violadas las mujeres en el lecho conyugal, estupradas las hijas al lado de su mismo padre, robados los intereses, en una sola palabra muertes, robos, heridas de todo genero y el castigo? Ninguno? Jamás se ve ahorcar a un matador, ni a un ladron. Se vierte con placer la sangre de un ilustre ciudadano y se economiza con desverguenza la de un malvado. Desgraciada Epoca!».

En este marco, que se pidiera este castigo en un acto sin violencia y con devolución previa de los efectos tenía que ver con su realización en un ámbito clave de la economía local tal como era el del tráfico mercantil en carretas venidas desde el que constituía el principal mercado para Mendoza, Buenos Aires, y todo ello en el crítico contexto económico de la primera mitad de 1824. No obstante, resulta sugerente también que el juez no diera lugar al exagerado pedido del fiscal y dictase 2 años de presidio en obras públicas para los acusados, cuadrando esta pena mucho mejor con las que se solían imponer por este tipo de robos $^{127}$.

\section{CONSIDERACIONES FINALES}

Este estudio nos ha permitido acercarnos a uno de los objetos centrales del temor de la élite local en los años en que intentaba configurar un orden republicano representativo en el nuevo marco provincial. En él pudimos confirmar que las coyunturas de inestabilidad política $(1820-1822 ; 1824 ; 1829)$ se relacionaron claramente con el incremento y violencia de los robos, aunque

126 El fiscal era el Dr. Juan Agustín Maza, hijo de Isidro Sáenz de la Maza y de Petronila Sotomayor, y en tanto tal perteneciente al núcleo del entramado familiar que había controlado los cargos capitulares, al menos hasta la Revolución. Su carrera política fue destacada, siendo decurión en 1815, diputado por Mendoza al Congreso de Tucumán en 1816 y llegando a ejercer por un día la gobernación en abril de 1824. Doctor en leyes por la Universidad de San Felipe, en Santiago de Chile, había impartido jurisprudencia en el Colegio de la Santísima Trinidad y fue activo partícipe en la organización de las instituciones judiciales de la provincia luego de 1820. Correas, 1992, vol. III: 178-180. Sobre el protagonismo de este grupo familiar en la vida política y comercial local y regional, Comadrán Ruiz, 126 (Santiago de Chile, 1958): 77-127.

127 Marzo de 1824, AHM, carpeta 446, doc. 2. 
no en la misma la línea que Belzunces había marcado para Luján (Buenos Aires), esto es, en el aumento de la presión reclutadora sobre ciertos sectores sociales que entraban en el círculo vicioso de reincidencia delictiva ${ }^{128}$. En este sentido, hemos visto que en Mendoza los azotes siguieron siendo los castigos predominantes, pero sí resulta claro que la contracción económica y el desorden institucional estimularon y facilitaron los ataques contra la propiedad. Y si bien como en la jurisdicción bonaerense el abigeato conformó el robo más común, no fue el más duramente penado, que lo fue, en cambio, el que atacaba dos aspectos nodulares de la hacienda local: el circulante monetario y el comercio (al menudeo y de tráfico regional).

En efecto, si bien los esfuerzos por evitar la circulación de artículos ilegalmente adquiridos comenzaron ya en la colonia, en estas épocas en que la crisis económica se profundizó con la caída del mercado vitícola mendocino y la desestructuración del circuito colonial, no era extraño que se intentaran fortalecer los controles sobre el comercio, sobre todo cuando en los meses centrales del año la actividad se contraía y la reventa de efectos robados (de pulpería, carne y aperos) se volvía un rubro alternativo para obtener recursos en sujetos que dependían de un mercado laboral estacional, y no sólo peones y jornaleros, sino también artesanos (herreros y plateros) y carniceros que buscaban proveerse de artículos para intercambiar por dinero o directamente por los que necesitasen para satisfacer sus necesidades básicas o, también, de ocio. Los expedientes muestran, de hecho, que por estas vías los subalternos lograban proveerse de metálico, tener ingresos adicionales o simplemente apostar en juego, poniendo en discusión la tesis historiográfica tradicional sobre la escasez de circulante monetario.

Si bien las cifras muestran, aun con los riesgos heurísticos, un aumento considerable de los robos en comparación con décadas anteriores y con otros delitos en la misma época, los miedos de la élite se vinculaban con los que afectaban sus actividades económicas (y recordemos la pena de muerte pedida por un fiscal para unos peones que habían robado en una tropa de carretas), y sus esferas domésticas. Así, siguiendo la tradición jurídica indiana, castigaron duramente los ataques en domicilios, en tiendas cerradas o celdas religiosas; es decir, robos calificados que implicaban violaciones de espacios privados.

Una red judicial inferior más eficiente con vecinos habituados a denunciar delitos ante su decurión, sumado a la distribución de puniciones según sus mayores temores, permitieron a la élite concentrarse en la defensa de las propiedades y el comercio que, en medio de la crisis institucional y la lucha

128 Belzunces, 2011: 59 y 127. 
facciosa, se vieron afectados. Y no hay que olvidar que un gran porcentaje de reos y sospechosos eran migrantes, no siempre peones, pero sí mayoritariamente, lo cual explica la necesidad de acceder a otras fuentes de recursos cuando los contratos disminuían y no se tenían vínculos parentales o comunitarios de protección, aunque también se vinculaba con la desconfianza de los moradores que encontraban en estos sujetos chivos expiatorios para sus conflictos. Pareciera, entonces, que no se trataba de que estos últimos delinquieran menos que los forasteros sino de que los recién llegados no disponían de relaciones a las cuales acudir ante necesidades materiales o cuando se enfrentaban a la justicia, y aquí la opinión de jueces menores y vecinos era un arma contra la cual no podían defenderse.

\section{BiBLIOGRAFÍA}

Academia Nacional de la Historia, Actas de la Legislatura de Mendoza (Años 18201827), Buenos Aires, Academia Nacional de la Historia, 1988, vol. I.

Barriera, Darío, "Voces legas, letras de justicia. Culturas jurídicas de los legos en los lenguajes judiciales (Río de la Plata, siglos XVI-XIX)", Tomás Mantecón Movellán (ed.), Bajtin y la historia de la cultura popular: 40 años de debate, Santander, $\mathrm{Pu}$ bliCan-Universidad de Santander, 2008: 347-368.

Barriera, Darío (coord.), Justicia y fronteras. Estudios sobre historia de la justicia en el Río de la Plata. Siglos XVI-XIX, Murcia, Universidad de Murcia/Red Columnaria, 2009.

Barriera, Darío (coord.), La justicia y las formas de la autoridad. Organización política y justicia locales en territorios de frontera. El Río de la Plata, Córdoba, Cuyo y Tucumán, siglos XVIII y XIX, Rosario, ISHIR/CONICET, 2010.

Barriera, Darío, "La justicia de proximidad, historia e historiografía (y viceversa)", XIV Encuentro de Historia Regional Comparada, Siglo XVI a mediados del Siglo XIX, Santa Fe, PIHSER, 2012.

Belzunces, Federico, "Los ojos de la justicia en la mirada del Estado: orden, delito y castigo (Guardia de Luján 1821-1852)", tesis de licenciatura, Universidad Nacional de Luján, 2011.

Boixadós, Roxana y Faberman, Judith, "Oprimidos de muchos vecinos en el paraje de nuestra habitación. Tierra, casa y familia en los llanos de la Rioja colonial", Boletín del Instituto de Historia Argentina y Americana "Dr. Emilio Ravignani", $3^{\circ}$ serie/31 (Buenos Aires, 2009): 11-42.

Bragoni, Beatriz, "Condiciones y estímulos en la recuperación de una economía regional. Prácticas mercantiles e instituciones empresariales en Mendoza (1820- 
1880)", María Alejandra Irigoin y Roberto Schmidt (comp.), La desintegración de la economía colonial. Comercio y moneda en el interior del espacio colonial (18001860), Buenos Aires, Biblos, 2003: 280-296.

Bragoni, Beatriz, "El tumulto y la plaza. Corporación y pueblo en la configuración del poder mendocino, 1824", en Beatriz Dávilo, Marisa Germain, Claudia Gotta, Analía Manavella, María Luisa Múgica (eds.), Territorio, memoria y relato en la construcción de identidades colectivas, Rosario, UNR Editora, 2004, vol. III: 211-218.

Candioti, Magdalena, "Altaneros y libertinos: la condición legal de los afroporteños y sus transformaciones en el Buenos Aires posrevolucionario (1810-1820)", ponencia presentada al XXVIII Congreso Internacional de la Asociación de Estudios Latinoamericanos: Repensando las desigualdades, Río de Janeiro, 2009.

Comadrán Ruiz, Jorge, "Las tres casas reinantes de Cuyo", Revista chilena de Historia $y$ Geografía, 126 (Santiago de Chile, 1958): 77-127.

Correas, Jaime, Historias de familias, Mendoza, Diario Uno, 1992, vol. III.

Di Meglio, Gabriel, "Ladrones. Una aproximación a los robos de Buenos Aires, 18101830", Andes, 17 (Salta, 2006a): 15-49.

Di Meglio, Gabriel, ¡Viva el bajo pueblo! La plebe urbana de Buenos Aires y la política entre la Revolución de Mayo y el rosismo, Buenos Aires, Prometeo, 2006b.

Elias, Norbert, The Civilizing Process. Sociogenetic and Psychogenetic Investigations, Oxford, Basil Blackwell, 1978-1982, 2 vols.

Faberman, Judith, "Familia, ciclo de vida y economía doméstica. El caso de Salavina, Santiago del Estero en 1819", Boletín del Instituto de Historia Argentina y Americana "Dr. Emilio Ravignani", $3^{\circ}$ serie/11 (Buenos Aires, 1995): 33-59.

Fontaine, Laurence, "Les villageois dans et hors du villaje. Gestion des conflits et contrôle social des travailleurs migrant originaires des montagnes françaises (fin du XVIIme. Siècle-milieu du XIXme. Siècle)", Crime, Histoire et Sociétés/Crime, History and Societies, 1/1 (Genève,1997): 71-85.

Foucault, Michel, La vida de los hombres infames, La Plata, Altamira, 1996.

Foucault, Michel, Surveiller et punir. Naissance de la prison, Paris, Gallimard, 1975.

Fradkin, Raúl (comp.), El poder y la vara. Estudios sobre la justicia y la construcción del Estado en el Buenos Aires rural, Buenos Aires, Prometeo, 2007.

Fradkin, Raúl (comp.), La ley es tela de araña. Ley, justicia y sociedad rural en Buenos Aires, 1780-1830, Buenos Aires, Prometeo, 2009.

Garavaglia, Juan Carlos, Pastores y labradores de Buenos Aires. Una historia agraria de la campaña bonaerense, 1700-1830, Buenos Aires, Ediciones de la Flor, 1999a.

Garavaglia, Juan Carlos, Poder, conflicto y relaciones sociales. El Río de la Plata, XVIII-XIX, Rosario, Homo Sapiens, 1999b. 
Garnot, Benoît, "Justice, infrajustice, parajustice et extrajustice dans la France d' Ancien Régime", Crime, Histoire et Sociétés/Crime, History and Societies, 4/1 (Genève, 2000): 103-120.

Hudson, Damián, Recuerdos históricos de la Provincia de Cuyo, Mendoza, EDIUNC, 2008, vol. II.

Gutiérrez, José Marcos, Práctica criminal de España, Madrid, Imprenta de Don Fermín Villalpando, 1819, vol. III.

Kessler, Gabriel, El sentimiento de inseguridad. Sociología del temor al delito, Buenos Aires, Siglo XXI, 2009.

Mantecón Movellán, Tomás, "Meaning and social context of crime in preindustrial times: Rural society in the North of Spain, 17th and 18th centuries", Crime, Histoire et Sociétés/Crime, History and Societies, 1/2 (Genève, 1998): 49-73.

Mantecón Movellán, Tomás “The Patterns of Violence in Early Modern Spain”, The Journal of The Historical Society, 7/2 (Boston, 2007): 229-264.

Mantecón Movellán, Tomás, "Ejecuciones públicas y cultura del sufrimiento en la corte pontificia: Roma y sus contextos del Antiguo Régimen”, José Millán, Manuel Rivero Rodríguez, Gijs Versteegen (coords.), La corte en Europa: Política y religión (siglos XVI-XVIII), Madrid, Polifemo, 2012, vol. III: 1905-1932.

Molina, Eugenia, "Criminalidad y revolución. Algunas consideraciones sobre las prácticas delictivas en Mendoza entre 1810 y 1820", Boletín de avances del CESOR, 6 (Rosario, 2009): 133-153.

Molina, Eugenia, “Tras la construcción del orden provincial: las comisiones militares de justicia en Mendoza, 1831 y 1852", Darío Barriera (coord.), La justicia y las formas de la autoridad. Organización política y justicia locales en territorios de frontera. El Río de la Plata, Córdoba, Cuyo y Tucumán, siglos XVIII y XIX, Rosario, ISHIR/CONICET, 2010: 83-105.

Molina, Eugenia, "Relaciones sociales, delito y orden comunitario: judicialización de los conflictos en Mendoza, 1770-1810", Revista del Instituto de Historia del Derecho, 41 (Buenos Aires, enero-junio 2011a): 163-198.

Molina, Eugenia, “ ¿Cómo crear un orden? Discursos y debates en torno de las funciones de justicia en el contexto de configuración del orden provincial. Mendoza, 1820-1828", ponencia presentada a las XIII Jornadas Interescuelas/Departamentos de Historia, Catamarca, 2011b.

Molina, Eugenia, "Delitos, política y justicia: la trama tejida en los comienzos de la autonomía provincial. Mendoza, 1820-1829”, II Jornadas interdisciplinarias de investigaciones regionales. Enfoques para la historia, Mendoza, INCIHUSA/CONICET/AGENCIA, 2011c.

Molina, Eugenia, “Orden, seguridad y justicia en los comienzos de la autonomía provincial: delitos y política en Mendoza, 1820-1829”, Ricardo Salvatore y Osvaldo 
Barreneche (comp.), El delito y el orden en perspectiva histórica. Nuevos aportes a la historia de la justicia penal y las instituciones de seguridad en Argentina, Rosario, Prohistoria, 2013: 25-45.

Parolo, Paula, "Ni súplicas, ni ruegos". Las estrategias de subsistencia de los sectores populares en Tucumán en la primera mitad del siglo XIX, Rosario, Prohistoria, 2009.

Salvatore, Ricardo, Subalternos, derechos y justicia penal. Ensayos de historia social y cultural argentina 1829-1940, Barcelona, Gedisa, 2010.

Schwerhoff, Gerd, "Criminalized violence and the process of civilization: a reappraisal”, Crime, Histoire et Sociétés/Crime, History and Societies, 6/2 (Genève, 2002): 103-126.

Scott, James Los dominados y el arte de la resistencia. Discursos ocultos, México, Ediciones Era, 2000.

Seghesso de López Aragón, María Cristina, Historia constitucional de Mendoza, Mendoza, Instituto Argentino de Estudios Constitucionales y Políticos, 1997.

Spierenburg, Pieter, The Spectacle of Suffering. Executions and the Evolution of Repression, Cambridge, Cambridge University Press, 1984.

Spierenburg, Pieter, "Violence and the civilizing process: does it work?", Crime, Histoire et Sociétés/Crime, History and Societies, 5/2 (Genève, 2001): 87-105.

Fecha de recepción: 13 de agosto de 2012.

Fecha de aceptación: 14 de noviembre de 2012.

The problem of robbery: from elite fears to lower-class subsistence practices. Mendoza (Río de la Plata), 1820-1831

This essay focuses on a specific study of thefts that occurred in the jurisdiction of Mendoza at the time of the formation of the provincial state. To do this, we will analyze judicial cases and government documents preserved in the Historical Archive of Mendoza. The aim of the study is to determine if the fears of the local elite, in the face of what they interpreted as growing post-revolutionary social conflict, were borne out by the information given in the sources; furthermore, we also aim to detect on which offenses against property they prioritized surveillance and punishment.

KeY WORDS: criminality; thefts; elites; subalterns sectors. 